Aletria, Belo Horizonte, v. 29, n. 3, p. 117-132, 2019

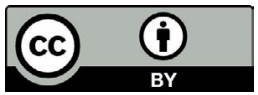

\title{
EI ensayo y la crítica literaria en Cuba: el malestar de la cultura y una luz al final del túnel
}

\section{The Essay and the Literary Criticism in Cuba: The Malaise of the Culture and a Light at the End of the Tunnel}

\author{
Ronald Antonio Ramírez Castellanos \\ Universidad de La Habana (UH), La Habana / Cuba \\ ronaldantonio.ramirez@fenhi.uh.cu
}

Resumen: Este artículo propone un examen de la producción ensayística y la crítica literaria en Cuba en los últimos años, zonas preteridas de la evaluación metacrítica contemporánea en el panorama cultural de la Isla. Pretendo indicar los estados de opinión sobre esta actividad, las problemáticas que impiden su desarrollo y las acciones emprendidas por el Centro Teórico-Cultural Criterios de La Habana, y su fundador Desiderio Navarro. De igual modo, visibilizo las contradicciones entre los estudiosos de la cultura nacional respecto al tema y las posibilidades existentes para revertir esta situación en un futuro inmediato.

Palabras clave: ensayo; crítica-literaria; cultura; Criterios; problemáticas; literatura cubana.

\begin{abstract}
This paper proposes an examination of essays and literary criticism in Cuba over the past years, zones that were neglected by the meta-critical contemporary analysis in the cultural panorama of the Island. I intend to point out the status of opinions on this activity, the problematics that hinder its development and the actions undertaken by the Criterios Theoretical Cultural Center of Havana, and his founder Desiderio Navarro. Likewise, I expose the contradictions between the intellectuals of the national culture in relation to the theme and the existent possibilities to revert this situation in an immediate future.
\end{abstract}

Keywords: essays; literary criticism; culture; Criterios; problematics; Cuban literature. 
Plena la culturología de esclarecimientos... la crítica en Cuba, en este mismo minuto, es pequeña y pedestre. Porque son escasos los cosmos, porque no abundan las poéticas críticas, porque los inventarios aplazan la lubricidad del pensar. Dolor de ausencia, tristeza del alma, bolero de la cultura. ${ }^{1}$

Al evaluar el proceso evolutivo del ensayo y la crítica literaria actuales en Cuba intentaré una visión historiográfica de conjunto, en la medida de lo posible, pues resulta difícil establecer los límites de su desarrollo en el contexto intelectual de la Isla, toda vez que, tanto el ensayo, como soporte genérico fundamental para el ejercicio de la teoría, y la crítica literaria, afloran estrechamente mancomunados. Sin pretender un mapa exclusivamente referativo de obras y autores que agote el potencial analítico de sus estéticas -en realidad un estudio todavía en ciernes- me interesa visibilizar el estado disfuncional de esta actividad intelectual y las potencialidades existentes para revertir tal situación.

De este modo direccionaré mis criterios en la exposición de un mainstream que genera un malestar cultural, las líneas en las cuales se bifurca el estado de opinión respecto al tema, sus oasis en medio de las convulsiones intelectuales, así como las proyecciones que indician, tal vez, una posible salida que supere las actuales coyunturas. Con todo, en este artículo aporto, más que una comprensión preliminar del proceso, una continuidad en los empeños valorativos efectuados hasta el momento por la historiografía literaria nacional sobre el ensayo teórico literario y la crítica cubana contemporáneas. Este propósito forma parte de una intencionalidad mayor: la atención a esas zonas genéricas, hoy difíciles de acceder y estudiar debido a la dispersión de autores y obras que experimenta el campo cultural cubano de los últimos años.

Parto de un criterio bastante generalizado en lo concerniente a la actividad crítica y ensayística producida hasta hoy dentro de Cuba: la ausencia de una sistematización crítica antes que de una preocupación sobre las posibilidades de ejercerla de manera cabal. Ese diagnóstico apunta al carácter utilitario del desempeño crítico, los modos en que tal actividad demuestran la eficacia a la que aspira el "intelectual orgánico" comprometido con las problemáticas culturales de su contexto histórico. Carlos Alé Maurí considera que en Cuba

${ }^{1}$ CABALLERO. Con odio y con amor, como un hombre. Sentido y placer del crítico (cubano). 
[a] pesar de todo no ha dejado de haber crítica. Los problemas no son de existencia, sino de suficiencia, de eficacia, de realización en el sentido de disponer de medios coherentes, regulares y especializados, como espacios que puedan servir de abrevaderos de orientación para el público. Me aventuro a resumir las acusaciones que se le hacen a la crítica: inactualidad, desactualización conceptual -que es otra cosa- y pérdida o dificultad de estilo. Son tópicos ya bastante discutidos. ${ }^{2}$

En este orden, Soler Palomino resalta las dificultades que laceran la actividad de la crítica literaria, en particular, la diversidad de espacios de socialización que divulguen y promocionen esta actividad en el ámbito cultural cubano. Tales espacios operan, por lo regular, en instituciones y proyectos culturales que jerarquizan una postura casi siempre habanocentrista que limita las posibilidades de expresión de la crítica literaria y cultural efectuada, por ejemplo, en los núcleos culturales formados al interior de la Isla. El papel de las publicaciones culturales, casi siempre dependientes del apoyo estatal, todavía resulta, en este sentido, muy pobre. La razón obedece a problemas también económicos que coadyuvan a la irregularidad de sus salidas lo cual impide la divulgación en tiempo de las obras; también a las posturas conservadoras y dogmáticas de las políticas editoriales y culturales en el país que temen al ejercicio de la polémica y al diálogo crítico con los lectores.

A juicio de Soler, se insiste en las relatorías epidérmicas que evaden posicionamientos de mayor calado en la valoración del ensayo y la crítica, en las cuales casi siempre el criterio historiográfico oficial privilegia el estudio del primero antes que del segundo; la escogencia de obras con mayor visibilidad en escenarios culturales nacionales antes que provinciales, hecho que incide en la evaluación deficiente de su desarrollo en el ámbito literario cubano. De esa manera considera que la crítica en Cuba

se difunde a través de las aperturas infértiles, los retazos de esencias literarias que se comprometen más allá del núcleo creador de la ficción y pasa por el tapiz del centro de poder cultural. Se diluye nuestra crítica establecida, dígase los consagrados en el medio, en la indiferencia a los objetos culturales desacralizados que los pondrían fuera del foco

${ }^{2}$ RIVERÓN. Para llegar a Jerusalén, p. 7. 
enquistado en el que se encuentran, y aquí volvemos al tratamiento de las figuras y las contradicciones ya pasadas. Es casi nulo el tratamiento de los problemas literarios y tendencias desarrolladas en la Cuba profunda. Existe una precaución excesiva de los más jóvenes para abordar su propia realidad por no caer en el terreno del llamado sindrome de la sospecha. ${ }^{3}$

Estos criterios convergen en la identificación de una crítica literaria paternalista que tiende, por lo regular, a distorsionar los nexos entre el crítico, la obra estudiada y el contexto sociocultural en que surge. Conviene resaltar las problemáticas detectadas por Fowler en su revisión de la crítica cubana a finales del siglo XX, en tanto advierte la ausencia de una publicación especializada capaz de potenciar una cultura crítica en los modos de aprehensión de las prácticas culturales y literarias en Cuba, el abandono de los espacios de discusión teórica y crítica en las instituciones culturales y académicas capaces de llevar a su máxima expresión este ejercicio, las limitaciones de publicación en revistas con larga tradición en el género, tanto en el campo cultural como el académico; el empobrecimiento bibliográfico de los fondos bibliotecarios, lo cual impide la actualización teórica en los estudios literarios, tan necesaria para la función crítica, y el divorcio entre la comunidad académica con las instituciones culturales en el país que ralentiza no solo la práctica literaria, sino los modos de aprehender sus relaciones inter/trans/multidisciplinares respecto a otras zonas de la cultura:

En sentido general, que sea tan escaso el estímulo en la mayoría de ellas al pensamiento interdisciplinario, a la publicación de autores cubanos que pretendan someter a renovación el arsenal teórico-crítico del marxismo y sus aparatos categoriales y metodológicos; que concedan tan poca atención a los procesos de la cultura popular y de masas; que hayan sido incapaces de localizar las angustias centrales del país y su cultura, lo mismo en su presente que en sus futuros previsibles, y plantéarselo en términos de debates imprescindibles. ${ }^{4}$

\footnotetext{
${ }^{3}$ SOLER PALOMINO. La crítica literaria en la Cuba actual: espacios y aperturas, $\mathrm{p}$. 71, cursivas del autor.

${ }^{4}$ FOWLER. Bodas de Cenicienta y Tántalo: metacrítica en Cuba, p. 15.
} 
Si bien esta ha sido la realidad contextual que particulariza el desempeño de la crítica y la teoría literaria en la isla en sentido general, es justo reconocer la existencia de una importante institución cultural que ha intentado revertir este complejo panorama. Me refiero a la labor del Centro Téorico-Cultural Criterios fundado por Desiderio Navarro en 1972, y que, en palabras de Fernández Retamar, representa una de "las aventuras intelectuales más extraordinarias de nuestra cultura". ${ }^{5}$

No es posible hablar de las particularidades de la teoría, la ensayística y la crítica literaria y cultural de los últimos años en Cuba sin referir los aportes de esta institución, y en particular, de la obra de Desiderio Navarro, sobre todo porque el surgimiento y desarrollo de las actividades científico-teóricas desplegadas por él contribuyeron de manera invaluable al conocimiento de la teoría cultural mundial, el pensamiento teórico relacionado con la praxis literaria, artística, la estética, la filosofía contemporánea y la semiótica, entre otros aspectos de medular interés en el campo de los cultural studies. En medio del desvalimiento insular respecto a esos temas, el centro Criterios representó un oasis que nutrió a gran parte de la producción intelectual de la Isla desde la década de los años setenta hasta la actualidad.

Este proyecto tuvo su génesis en las páginas de una de las revistas culturales de mayor alcance en el país, La Gaceta de Cuba, desde 1972. El boletín Criterios logró posteriormente su independencia editorial de esta publicación debido a la amplia aceptación entre los intelectuales cubanos, hasta su conversión en revista homónima de carácter internacional (Revista Internacional de Teoría de la Literatura y las Artes, Estética y culturología). Ya en la etapa finisecular del siglo XX adquiere su connotación de Centro Teórico Cultural, con sede propia en el emblemático edificio que ocupa el Instituto Cubano del Arte e Industria Cinematográficos (ICAIC) en su noveno piso. En sus locales, esta nueva institución patrocinó, con el apoyo de los asesores culturales de las embajadas europeas mayoritariamente, la celebración de eventos teóricos y conferencias magistrales impartidas por cultorólogos, semiólogos, filósofos de renombre como Iuri Lotman, Patrice Pavis, Stefan Morawski, Boris Groys, Henryk Markiewics, por solo mencionar algunos.

Junto a Desiderio Navarro, la colaboración del profesor de Teoría Literaria y Análisis de Textos de la Universidad de La Habana, Salvador Redonet Cook, implementaba una actividad complementaria en el

${ }^{5}$ RETAMAR FERNÁNDEZ. Sobre “Criterios” y Desiderio Navarro, p. 6. 
proceso de enseñanza-aprendizaje al frente de su cátedra en la Facultad de Artes y Letras de esa alta casa de estudios. Respecto a los nexos entre la actividad intelectual de Navarro y Redonet, sus intervenciones en el campo literario cubano, la profesora y ensayista cubana Teresa Delgado explica lo siguiente:

Durante el Quinquenio Gris, Desiderio Navarro había comenzado la publicación de sus traducciones de textos teóricos básicamente referidos a la literatura, algunos de los cuales serían utilizados por Redonet en sus cursos. Desde un punto de vista metodológico, a Redonet le interesaba el análisis estructural del texto narrativo literario, perspectiva teórica que ya se encontraba representada en la selección de artículos publicados por Desiderio Navarro [...], sin que hubieran concebido un proyecto común, sus trabajos se complementaban armónicamente. ${ }^{6}$

Mientras Navarro desglosaba un camino expedito con posibilidades metodológicas de amplia proyección en el campo cultural nacional, Redonet aplicaba los procedimientos teóricos y contribuía a la actualización permanente de los planes de estudios de las asignaturas Teoría Literaria I y II, Análisis de Textos y Semiótica, que posteriormente fueron perfeccionadas en las sucesivas versiones del Plan de Estudios de la Carrera de Letras para los tres centros educativos universitarios donde la misma se impartía en el país: además de la Universidad de La Habana, la Universidad Central de Las Villas, en la provincia de Villa Clara y la Universidad de Oriente, en Santiago de Cuba. De esta manera, surgía una respuesta a la demanda creciente de la intelectualidad cubana en la formación de egresados filólogos que se integrarían al espectro cultural cubano con una sólida preparación en el campo de la teoría y la crítica literaria, el arte y la culturología en su sentido más amplio.

La creación de la biblioteca "Salvador Redonet Cook" -como homenaje a su memoria luego de su fallecimiento- y su colección electrónica "Mil y un textos en una noche", presentada en los eventos teóricos de Criterios, quedó disponible al público lector de la isla, y en especial, a los centros educacionales de enseñanza universitaria donde se impartían carreras y asignaturas relacionadas con los más disímiles aspectos de la cultura, la literatura y las artes. "Mil y un textos..."

${ }^{6}$ DELGADO. Convergencias críticas: Desiderio Navarro y Salvador Redonet, p. 9. 
conformó más de cinco mil títulos entre artículos y libros reunidos y/o traducidos por Desiderio Navarro a lo largo de varias décadas, cuya vigencia en la actualidad resulta difícil de aquilatar. Cada volumen, distribuido en copias de discos compactos o dispositivos portátiles de almacenamiento de datos, comprendía textos escogidos en inglés, francés, italiano, portugués y español, clásicos y contemporáneos del pensamiento cultural de América del Norte, América Latina, Europa Occidental y Oriental, Asia y África, en los cuales se problematizan las diversas concepciones teóricas del arte, el teatro, el cine, la música, las culturas populares, los mass media, la estética, la filosofía y el pensamiento social, estudios culturales de género, raza, lesbianos-gay-queer, la antropología, la sociología, la semiótica de la cultura y por supuesto, la literatura. Por otra parte, esos textos fueron publicados en forma de libros ${ }^{7}$ gracias a donativos presupuestarios y gestos de buena voluntad de las embajadas de Francia, Suiza, Polonia, Rusia y Alemania, así como al particular interés de sus autores, quienes, o bien cedían los derechos de publicación de su obra en Cuba, o lo pagaban a las editoriales que los detentaban en sus países de origen. De esta forma, el aporte de Criterios a la cultura nacional contribuyó a la democratización de una información que, por lo regular, permanecía inaccesible hasta entonces para la comunidad intelectual cubana.

Hay, no obstante, otra zona en la producción intelectual de Navarro que recientemente es objeto de atención por parte de los estudiosos contemporáneos. Se trata de sus aportes a la comprensión de la praxis literaria insular a partir de la aplicación de los mismos presupuestos teóricos

\footnotetext{
${ }^{7}$ Por ejemplo, las compilaciones Intertextualité. Francia en el origen de un término y el desarrollo de un concepto (2001); Intertextualität 1. La teoría de la intertextualidad en Alemania (2002); Image 1. Teoría francesa y francófoca del lenguaje visual y pictórico (2002): de Patrice Pavis, El teatro y su recepción. Semiología, cruce de culturas y posmodernismo (2000); Árbol del mundo. diccionario de imágenes, símbolos y términos mitológicos (2001); El Posmoderno, el postmodernismo y su crítica en Criterios (2007), de Stefan Morawski: De la estética a la filosofía de la cultura (2006); de Boris Groys: Obra de arte total Stalin. Topología del arte (2005) y la compilación El pensamiento cultural ruso en Criterios (2009, 2 tomos) entre otros títulos importantes. La última publicación de Criterios, Denken Pensée Thought Mysl (2015-2016) en tres volúmenes, compendia lo más avanzado del pensamiento teórico-cultural europeo de los últimos años. Un cuarto volumen quedaría inconcluso con el fallecimiento de Desiderio Navarro el 7 de diciembre de 2017 en La Habana.
} 
de avanzada que él se encargaba de traducir y divulgar en el campo cultural cubano. Sobre este particular, la ensayista, académica y Premio Nacional de Literatura Margarita Mateo Palmer ha destacado lo siguiente:

En la diversidad de sus reflexiones puede encontrarse la más clara expresión de la poética que sustenta la empresa ciclópea desarrollada por él. Hace muchos años [...] Desiderio Navarro comenzó no solo a participar activamente en el mundo de la cultura, sino a meditar con el mayor rigor sobre la problemática estética que se debatía en aquellos complejos años sesenta. Este es el germen de un saber que, de modo sólido y coherente, se iría desarrollando a través del tiempo hasta llegar a convertirse en la más penetrante indagación sobre la teoría literaria, artística y de la cultura en Cuba. ${ }^{8}$

De esas contribuciones me interesa la medular caracterización de Navarro respecto a la crítica literaria en Cuba, cuya práctica adolecía de un sustento teórico-conceptual. Esas declaraciones formaron parte de una encuesta que realizara la revista Revolución y Cultura en 1981, más tarde compilada en su libro Cultura y marxismo. Problemas y polémicas (1986), a mi juicio, uno de los textos más trascendentales dentro de su producción personal:

Muchos de nuestros críticos siguen siendo tributarios de una concepción de la crítica literaria que la reduce al examen y valoración de obras aisladas o de las obras de un autor aislado. Escasean en grado sumo las generalizaciones sobre problemáticas, estilos, géneros y subgéneros, tipos, tendencias, procesos, etc., se suelen ver los árboles, mas no el bosque; las obras, mas no la estructura interna, el sistema de la literatura nacional, ni la evolución de ese sistema o estructura de estructuras. La imagen predominante de la situación de la literatura cubana en determinado momento es, gracias a cierta crítica, la de un archipiélago de singulares islas-obras (o islas-conjuntos-obras agrupadas por autores) que no guardan ninguna relación tipológica entre sí. Al propio tiempo, la imagen del proceso literario nacional que se limita a darnos esa crítica con sus sucesivas

\footnotetext{
${ }^{8}$ MATEO PALMER. La obra de Desiderio Navarro: ¿perros y gatos en un costal?, p. 35.
} 
instantáneas de obras individuales, recuerda la aporía eleática de la flecha, fija en cada momento de su vuelo en un punto del espacio y, por tanto, inmóvil. ${ }^{9}$

Navarro aprecia un salto cuantitativo de los registros críticoliterarios en el ámbito cultural nacional que, en cierta medida, superaban la "indigencia crítica" que Juan Marinello advertía en la cultura cubana. Sin embargo, en el aspecto cualitativo no distinguía los mismos resultados. Concebía la crítica literaria no solo como una práctica necesaria para la comprensión de la literatura cubana, sino también como un sistema integrador de la cultura más allá del ejercicio aislado del criterio. Es decir, como parte de una cultura literaria. De esta manera, su visión holística (marxista) del proceso, le permitió hablar en términos de una crítica literaria en tanto crítica de la cultura literaria en su conjunto y no exclusivamente de obras relacionadas con la literatura y sus especificidades genéricas.

Desde esta perspectiva, para Navarro, la noción de cultura literaria no responde a criterios de formación subjetiva de preferencias y lecturas, sino a un

[...] Conjunto de los fenómenos y procesos que participan en la comunicación social literaria de una sociedad dada: la difusión de las obras literarias -las editoriales, las revistas y periódicos, la radio y la televisión, etc.-; la profesionalización y las condiciones sociales de la escritura-los derechos de autor, los concursos y premios, los talleres literarios, etc.-, y las condiciones sociales de la lectura -la escuela, las bibliotecas, etc.-. Las obras literarias son un correlato, un eslabón de esa cultura, de ese sistema dinámico. ${ }^{10}$

Al mismo tiempo -y a mi juicio, lo más importante-, resulta interesante su percepción de la crítica como un desempeño intelectual que exige, también, una actitud moral. No era la carencia de información teórica lo que afectaba en gran medida el trabajo del intelectual cubano de esos años, ni los escasos espacios de divulgación de la actividad crítico-literaria, sino problemáticas de carácter ético que torpedeaban su desarrollo tanto a nivel gremial como en la recepción de lo específico

\footnotetext{
${ }^{9}$ NAVARRO. Cultura y marxismo: Problemas y polémicas, p. 426-427.

${ }^{10}$ NAVARRO. Cultura y marxismo: Problemas y polémicas, p. 427.
} 
literario. La "blandenguería", el "sociolismo" y el arribismo, términos muy comunes en la norma popular cubana, son empleados de manera directa por Navarro para realizar una radiografía de la actividad crítico-literaria ejercida hasta ese momento en el panorama cultural. Estos neologismos del vernáculo hacían referencia a la crítica que soslaya las deficiencias en la práctica cultural, con el propósito de esquivar posibles represalias permeadas de posturas dogmáticas y conservadoras; al acomodamiento acodado en la cobardía intelectual que prefiere el mutismo ante los defectos de una obra, en particular cuando su autor es considerado un "consagrado" o un funcionario de la cultura; al "compadreo" o amiguismo que pondera valores literarios inexistentes o reales; y a "la deformación extrema" de la ética en la labor del crítico. Se trata, en síntesis, de un alpinismo o prostitución intelectual que pondera hasta la exageración valores inexistentes o reales de una obra y su autor, por escasos que fueran, con el propósito de obtener posicionamientos en puestos de dirección en instituciones culturales, mecenazgos entre funcionarios de la cultura, o bien el consentimiento entre escritores que temen ver su creación artística despedazada por motivos de rencillas y enemistades, o en su defecto, por el mero ejercicio de crítica intelectual honesta:

Ya estos fenómenos, por sí solos, dejan de suponer que el mal no nace en la crítica o, en todo caso, no exclusivamente en ella. Si ciertos críticos temen buscarse problemas, o gustan de hacer obsequios, o procuran obtener beneficios a través de la actividad crítica, es porque la experiencia (propia o ajena) les ha enseñado que muchos escritores no quieren en modo alguno objeciones -por objetivas que sean -, sino solo elogios - por infundados que sean-, y que, por las primeras, premian con maledicencias, maquinaciones y hasta "cierres" y otras represalias administrativas que estuvieran a su alcance, y, por los segundos, con un recíproco "bombo y platillo", promociones, "palancas" u otros favores. Y, más aún, esos críticos saben que, a causa de males análogos, en tales o cuales publicaciones sus reparos a las obras de ciertos autores -por bien argumentados que estuvieran- nunca irían a imprenta y que, en cambio, unas cuantas loas impresionistas sobre esas obras serían a priori bien recibidas y prontamente publicadas en lugar destacado. Pero aquí habría que hablar también del "enemiguismo", con su renuencia a publicar 
críticas sobre un determinado autor que no tengan un saldo desfavorable para este. ${ }^{11}$

Este reclamo respecto al posicionamiento ético del intelectual ante la crítica, conserva una extraordinaria vigencia en el presente cultural cubano. Si bien, como veremos, se aprecia un registro cualicuantitativo en los textos publicados a partir de las primeras décadas del presente siglo, las deformaciones intelectuales todavía mellan el desempeño de la crítica literaria en el país.

Con la democratización de las posibilidades de publicación de textos no solo en las editoriales nacionales, generalmente radicadas en La Habana, sino también en las casas editoriales al interior del país, la ensayística en la isla, un género fundamental para la dilucidación teórico-crítica de la literatura cubana contemporánea, adquiere un aire renovador que todavía no ha sido posible justipreciar en toda su magnitud, principalmente en las dos primeras décadas del siglo XXI. Algunos estudios recientes, como el de Ivette Fuentes, ${ }^{12}$ desde la considerada historiografía oficial en la Isla, centran su atención en las particularidades de esa exégesis, sobre todo en el período1989-1999. ${ }^{13}$ Las indagaciones socio-culturales, estudios teóricos y panoramas respecto a los orígenes y tradición de la literatura cubana, así como sobre la literatura artística y universal, son algunos de los deslindes temáticos del género en esos años que privilegian el escrutinio de tópicos relativos a la identidad nacional, las implicaciones sociales de la literatura de la época y el sutil abordaje de lo político en algunos temas que atraviesan las peculiaridades de la cubanía y su inserción contextual, los nexos entre el sujeto literario, conflictos existenciales y sus interrelaciones con el mapa sociocultural; la perspectiva teórica que aporta caracterizaciones panorámicas, genéricas y generacionales, así como la verticalidad en los adentramientos a las exégesis literarias - poéticas, narrativas o dramáticas. De igual forma, el énfasis en temáticas y/o etapas específicas del hecho literario, las cuales integran deslindes cronológicos, combinados con los análisis textuales y paratextuales; lo reflexivo-teórico respecto a cuestiones culturales de actualidad dentro de los Cultural studies; la posmodernidad en la literatura cubana, entre otras indagaciones culturológicas relacionadas

\footnotetext{
${ }^{11}$ NAVARRO. Cultura y marxismo: Problemas y polémicas, p. 430.

${ }^{12}$ FUENTES. Panorama del ensayo y la crítica, p. 674-688.

${ }^{13}$ FUENTES. Panorama del ensayo y la crítica, p. 674-688.
} 
al contexto, son algunos de los núcleos temáticos que tipifican el género ensayístico en Cuba, según Fuentes.

Sin embargo, hay un aspecto polémico en cuanto a su análisis, y tiene que ver con su criterio respecto a esta producción ensayística de autores cubanos tanto dentro como fuera de la Isla. Sobre este particular, indica: "[...] conceptualmente el ensayo y la crítica en este período no varían mucho entre el escrito en Cuba y el realizado fuera del nuestro territorio". ${ }^{14}$ A mi juicio, hay una variación medular, justo en el abordaje "revisionista", descentrado del anquilosamiento en una retórica a ratos desfasada, repetitiva, respecto a los modos que, desde el prisma filosófico, político, histórico y literario manejan los discursos de determinados intelectuales con una amplia obra en el campo cultural cubano.

Quizá por ello Rafael Rojas afirme que "[h] hablar hoy, de grupos intelectuales en Cuba, de una ciudad letrada, es aferrarse a una ficción estéril". ${ }^{15}$ Su observación detecta una fisura en la evolución del pensamiento cultural insular que, maniatada a los dogmatismos y conservadurismos de la ideología oficialista, elude una postura crítica en los acercamientos a la realidad social y cultural del país. Sobre los vínculos entre los intelectuales cubanos y sus relaciones, convergencias, rupturas y direccionamientos crítico-ideológicos con la política cultural del Estado comunista, hay posiciones encontradas que, en no pocas ocasiones han generado fértiles debates. ${ }^{16}$ Si bien Rojas detecta una ruptura formal y conceptual en las prácticas ensayísticas que intentan una rescritura de la visión teleológica de la historia cultural de la nación cubana, esa transparencia en su forma textual todavía sigue expuesta "al dedo de la censura". ${ }^{17}$ De este modo, a diferencia de otros géneros dentro de la tradición literaria cubana, Rojas niega la existencia de una "lógica ascensional" en el desarrollo de la ensayística cubana en la etapa, y ello se debe al modo en que los intelectuales participan de una actividad cultural alienada, a su juicio, "que junta sus argumentos en publicaciones precarias, silenciosos debates y sombrías veladas. No creo que este grupo tenga plena conciencia de su corporeidad $[\ldots] .^{18}$

\footnotetext{
${ }^{14}$ FUENTES. Panorama del ensayo y la crítica, p. 674.

${ }^{15}$ ROJAS. Isla sin fín: Contribución a la crítica del nacionalismo cubano, p. 216.

${ }^{16}$ Sobre este particular puede verse la polémica entre Arturo Arango y Rafael Rojas, publicada en la revista Temas. Cf. ROJAS. Diáspora, intelectuales y futuros de Cuba, p. 144-151; ARANGO. Para un diálogo entre sordos, p. 152-156.

${ }^{17}$ ROJAS. Isla sin fin: Contribución a la crítica del nacionalismo cubano, p. 217.

${ }^{18}$ ROJAS. Isla sin fin: Contribución a la crítica del nacionalismo cubano, p. 218.
} 
A pesar de esos criterios, con los cuales se puede concordar o no, lo cierto es que existe un sector intelectual que intenta el socavamiento de ese costado conformista, alineado al poder político y cultural que, en muy pocos casos, resulta aportador a la reflexión teórica. Se trata de un ala más radical, denostadora y polémica, aupada por intereses culturales que emprenden una voluntad de rescritura y revisión constante de los procesos histórico-culturales de la Isla. Es justo decir que ese sector, durante un tiempo radicado en la Isla y posteriormente marchado al exilio -debido también a su inconformidad con el marasmo cultural- ha publicado valiosos textos que lamentablemente la historiografía literaria oficial desconoce $-\mathrm{o}$ bien descalifica- por su postura tangencial con la política cultural de la Revolución. En este grupo se encuentran el propio Rafael Rojas, Iván de la Nuez, Ernesto Hernández Bustos, Antonio José Ponte, Emilio Ichikawa, Duanel Díaz, Rolando Sánchez Mejías, Walfrido Dorta, entre otros, como representantes de una generación que, entre finales de los ochenta y los primeros años de la década de los noventa, intentaron una ruptura formal y conceptual en el ejercicio crítico y ensayístico en la Isla, unido también a otros que todavía continúan sus desempeños en el ámbito cultural del país con textos renovadores dentro del género: Jorge Fornet, Víctor Fowler, Gustavo Arcos, Zaida Capote, Alberto Garrandés, por solo mencionar algunos de ellos. Vale aclarar que en este contexto surgen interesantes proyectos culturales en publicaciones periódicas que insuflaron a esta vanguardia ensayística un sentido generacional que, hasta años recientes, está siendo objeto de una revisión crítica por parte de las nuevas generaciones de intelectuales cubanos de ahora. Me refiero a los grupos-publicaciones como "Paideia" y "Diáspora's", las cuales resultan medulares a la hora de examinar la esfera intelectual del país por estos años.

Esta generación intelectual consolidada a principios de los noventa "reaccionó de forma violenta ante la supuesta literatura de ideas que se desarrolló en el período, bajo diferentes pretextos". ${ }^{19}$ En relación a la obra de los autores diaspóricos, textos publicados fuera de Cuba en su mayoría, no han tenido una amplia circulación en el país. Es por ello que, debido al desconocimiento general de esta producción, es posible identificar "una nueva ruptura en el campo intelectual de la Isla". ${ }^{20}$

${ }^{19}$ FOWLER. Presentación, p. 9.

${ }^{20}$ FOWLER. Presentación, p. 9. 
No obstante, una joven generación de críticos y teóricos de la literatura y la cultura cubanas, nacidos entre 1975 y 1980, principalmente, surge a finales de la primera década e inicios de la segunda de los años dos mil. En este sentido, el ensayista Arturo Arango, al evaluar la producción de esta nueva hornada de autores millenials, señaló:

En el campo de la cultura cubana, la mayoría de los jóvenes escritores y artistas cubanos se mantienen hoy en una tensa, permanente, negociación con los espacios institucionales, siempre bordeando los límites de la permisibilidad. A diferencia de lo que sucedía algunos lustros atrás, ahora las nuevas tecnologías permiten que, aun aquellas obras que antes necesitaban el apoyo de la industria y el mecenazgo estatal, puedan realizarse de manera precarias, pero independientes, y ello ha contribuido a que varíen los modos de las negociaciones. Frente a las instituciones, ya los artistas no ocupan una posición subalterna, y con frecuencia son aquellas las que se ven obligadas a colocarse a la defensiva. ${ }^{21}$

Aun cuando resulta imposible deslindar las directrices temáticas de los jóvenes escritores cubanos dedicados a la producción ensayística cultural, académico-investigativa o la labor de crítica literaria, sus intereses atraviesan, por lo regular, zonas problematizadoras de la literatura que no se apartan, con mucho, de los temas tratados por generaciones precedentes: los nexos inter/paratextuales y comparatísticos de la literatura cubana en sus diversas manifestaciones, épocas y autores, la focalización en la perspectiva de los estudios de género; los engarces panorámicos regionales y nacionales, visibilizando las zonas de silencio preteridas por la crítica y la historiografía literarias; las revisiones que exorcizan las demonizaciones respecto a la obra intelectual de autores condenados por la censura cultural debido a sus posturas anticomunistas; nexos de la literatura con la cultura popular, la perspectiva de focalización desde la sociología, los estudios visuales, danzarios y un largo etcétera.

Autores como Haydée Arango, Susana Haug, Dayron Oliva, Gerardo Muñoz, Alejandro Zamora, David Leyva, Leonardo Sarría, Juan Carlos Tabío, Elizabeth Mirabal, Carlos Velazco, Hamlet Fernández, Justo Planas, Roberto Rodríguez Reyes, Sandra del Valle, Ariel Camejo,

${ }^{21}$ ARANGO. Cuba, los intelectuales ante un futuro que ya es presente, p. 89. 
Yasmín Portales Machado, Gilberto Padilla Cárdenas, Helen Hernández Hormilla y otros más recientes como Yoandy Cabrera, Oscar Cruz, Javier Luis Mora, Ángel Pérez Velázquez, por solo mencionar algunos, participan de una práctica renovadora en los modos de ejercer la teoría y la crítica literaria y cultural no solo en sus libros ensayísticos, sino también en artículos aparecidos en publicaciones culturales y periódicas dentro y fuera de Cuba como La Siempreviva. Revista de Literatura y Libros, La Gaceta de Cuba, Unión, Revolución y Cultura, Hypermedia Magazine, La Jiribilla, La Letra del Escriba, El Caimán Barbudo, Islíada y Claustrofobias, por solo mencionar algunas de las vinculadas a la divulgación del ensayo y la crítica literaria.

Si bien aún es demasiado temprano para evaluar la producción de estos autores, al menos las convergencias estéticas de sus reflexiones revelan una mirada "más existencial, más introspectiva, exploran con dolor y agudeza su presente, y lo viven con igual intensidad, sin definir, al menos de manera explícita, esos futuros ideales o posibles que inquietan a otra parte de la intelectualidad cubana". ${ }^{22}$ Es válido apuntar que esta nueva generación ha adquirido un bagaje teórico que en muchos casos contiene un nivel constante de actualización debido a las crecientes posibilidades de acceso a las nuevas tecnologías de la información y a la red de redes, que, desde 2010, comienzan a tener una presencia significativa en la Isla. En lo adelante, que los direccionamientos estético-temáticos de esta renovada práctica escritural en Cuba implique un parteaguas en el proceso de desarrollo evolutivo del ensayo y la crítica, quizás ello represente un cambio medular en los modos de aprehensión de las particularidades de la cultura cubana. Se trata, en síntesis, de una tarea titánica que deberá hacerse, en el futuro, por parte de los historiadores y analistas de la literatura insular.

\section{Referencias}

ARANGO, Arturo. Cuba, los intelectuales ante un futuro que ya es presente. Temas, La Habana, n. 64, p. 80-90, oct.-dic. 2010.

ARANGO, Arturo. Para un diálogo entre sordos. Temas, La Habana, n. 66, p. 152-156, abr.-jun. 2011.

${ }^{22}$ ARANGO. Cuba, los intelectuales ante un futuro que ya es presente, p. 87. 
CABALLERO, Rufo. Con odio y con amor, como un hombre. Sentido y placer del crítico (cubano). La Gaceta de Cuba, La Habana, n. 1, p. 3-6, ene.-feb. 2000.

DELGADO, Teresa. Convergencias críticas: Desiderio Navarro y Salvador Redonet. In: La Gaceta de Cuba, La Habana, n. 5, p. 9-10, sep.-oct. 2017.

FOWLER, Víctor. Bodas de Cenicienta y Tántalo: metacrítica en Cuba. In: La Gaceta de Cuba, La Habana, n. 1, p. 14-19, ene.-feb. 2000.

FOWLER, Víctor. Presentación In: LASTRE, Reynaldo (org.); RICARDO, Sergio E. (coord.). Anatomía de una isla. Jóvenes ensayistas cubanos. Holguín: Ediciones La Luz, 2015.

FUENTES, Ivette. Panorama del ensayo y la crítica. Historia de la Literatura Cubana: La Revolución (1959-1988). La Habana: Letras Cubanas, 2008. p. 674-688, t. III.

MATEO PALMER, Margarita. La obra de Desiderio Navarro: ¿perros y gatos en un costal?. In: Casa de Las Américas, La Habana, n. 290, a. LXIX, p. 34-53, ene.-mar. 2018.

NAVARRO, Desiderio. Cultura y marxismo: Problemas y polémicas. La Habana: Editorial de Ciencias Sociales, 1986.

RETAMAR FERNÁNDEZ, Roberto. Sobre "Criterios" y Desiderio Navarro. In: La Gaceta de Cuba, La Habana, n. 5, p. 6, sep.-oct. 2017.

RIVERÓN, Rogelio. Para llegar a Jerusalén. In: La Gaceta de Cuba, La Habana, n. 1, p. 7-10, ene.-feb. 2000.

ROJAS, Rafael. Diáspora, intelectuales y futuros de Cuba. Temas, La Habana, n. 66, p. 144-151, abr.-jun. 2011.

ROJAS, Rafael. Isla sin fin: Contribución a la crítica del nacionalismo cubano. Miami: Ediciones Universal, 1998.

SOLER PALOMINO, Juventina. La crítica literaria en la Cuba actual: espacios y aperturas. In: La aguja en el pajar: contextos culturales cubanos. Granma: Ediciones Bayamo, 2013.p. 67-74.

Data de recebimento: 31 de janeiro de 2019. Aprovado em: 12 de agosto de 2019. 